\title{
EFEITO DA TEMPERATURA, EXTRAÇÃO E EMBEBIÇÃO DE SEMENTES NA GERMINAÇÃO DE Bactris maraja Mart. (ARECACEAE) ${ }^{1}$
}

\author{
Joelma Keith Rodrigues ${ }^{2}$, Maria Sílvia de Mendonça ${ }^{3}$ e Daniel Felipe de Oliveira Gentil ${ }^{4}$
}

\begin{abstract}
RESUMO - Bactris maraja Mart., palmeira nativa da Amazônia, ocorre em solos arenosos tipicamente às margens de lagos e igarapés. Apresenta grande importância ecológica, podendo ser propagada vegetativamente (touceiras) ou através de sementes. A propagação das palmeiras por meio de sementes geralmente apresenta germinação lenta, irregular e em baixa porcentagem. Dessa forma, a pesquisa teve como objetivo estudar os efeitos de diferentes temperaturas, períodos de secagem do pireno e extração da semente e períodos de embebição da semente na germinação. Foram realizados três experimentos: 1) Sementes foram submetidas a dois níveis de beneficiamento (sem remoção e com remoção do endocarpo) e seis diferentes temperaturas (20, 25, 30, 35, 40 e $26-40{ }^{\circ} \mathrm{C}$ ); 2) Pirenos foram submetidos a 0, 1, 2, 3, 5, 7, 9, 11 e 15 dias de secagem, em que em cada período foi feita a extração da semente; e 3) Sementes foram submetidas a 0, 1, 2, 3, 4 e 5 dias de embebição. As sementes submetidas à temperatura alternada de $26-40^{\circ} \mathrm{C}$ apresentaram maior porcentagem de germinação (acima de 60\%), não diferindo entre os níveis de beneficiamento. A secagem dos pirenos facilitou a extração das sementes. Contudo, a secagem e a extração das sementes reduziram a germinação e o vigor. Assim, o beneficiamento não é recomendado. A embebição das sementes por dois dias favoreceu a porcentagem e a velocidade de germinação.
\end{abstract}

Palavras-chave: Palmeira; Pireno; Beneficiamento.

\section{EFFECT OF TEMPERATURE, EXTRACTION AND SOAKING IN SEEDS IN THE GERMINATION OF Bactris maraja Mart. (ARECACEAE)}

\begin{abstract}
Bactris maraja Mart., palm tree native to the Amazon, typically occurs in sandy soils on the shores of lakes and streams. Presents great ecological importance and can be vegetatively propagated (clumps) or by seed. The spread of palm trees by seeds usually show slow, irregular and low percentage germination. Thus, the research aimed to study the effects of different temperatures, drying periods of pyrene and extraction of seeds and soaking periods of the seed in germination. Three experiments were conducted: 1) Seeds were subject to two levels of processing (with and without removal of endocarp) and six different temperatures $\left(20,25,30,35,40\right.$ and $\left.\left.26-40^{\circ} \mathrm{C}\right) ; 2\right)$ Pyrenes were subject to 0, 1, 2, 3, 5, 7, 9, 11 and 15 days of drying, in each period the seed extraction was made, 3) Seeds were subject to 0, 1, 2, 3, 4 and 5 days of soaking. Seeds subjected to alternating temperatures of $26-40^{\circ} \mathrm{C}$ showed higher germination percentage (above $60 \%$ ), with no difference between the levels of processing. Drying of pyrenes made seed extraction easier. However, drying and extraction of seeds reduced germination and vigor. Thus, the processing is not recommended. The seed soaking for two days favored the germination percentage and speed.
\end{abstract}

Keywords: Palm; Pyrene; Processing.

\footnotetext{
${ }^{1}$ Recebido em 20.11.2013 aceito para publicação em 07.08.2014.

${ }^{2}$ Programa de Pós-Graduação em Agronomia Tropical, Faculdade de Ciências Agrárias, Universidade Federal do Amazonas, UFAM, Brasil. E-mail: <joelmaeng@outlook.com>.

${ }^{3}$ Departamento de Ciências Fundamentais e Desenvolvimento Agrícola, Faculdade de Ciências Agrárias, Universidade Federal do Amazonas, UFAM, Brasil. E-mail: <msilvia@ufam.edu.br>.

${ }^{4}$ Departamento de Produção Animal e Vegetal, Faculdade de Ciências Agrárias, Universidade Federal do Amazonas, UFAM, Brasil. E-mail: <dfgentil@ufam.edu.br>.
} 


\section{INTRODUÇÃO}

A Floresta Amazônica compreende um rico acervo de espécies frutíferas nativas, das quais muitas são conhecidas apenas regionalmente. Nesse contexto, inserem-se as palmeiras, que constituem a família Arecaceae, que apresentam grande importância socioeconômica e são utilizadas em áreas tropicais na construção de habitação, na alimentação, na ornamentação, na medicina popular e no artesanato (LORENZI et al., 2004).

Apesar de algumas palmeiras serem propagadas vegetativamente, a maior parte das espécies desse grupo é propagada sexuadamente, isto é, por sementes, as quais geralmente apresentam germinação lenta, irregular e em baixa porcentagem, muitas vezes devido a mecanismos de dormência impostos pela própria semente (FERREIRA et al., 2010). Esses mecanismos têm sido atribuídos, em parte, aos envoltórios da semente, seja pela resistência mecânica dada à rigidez do endocarpo lenhoso, seja pela impermeabilidade à água (OROZCOSEGOVIA et al., 2003).

A remoção do endocarpo e a embebição das sementes em água podem favorecer a porcentagem e a velocidade da germinação (FERREIRA; GENTIL, 2006), bem como a emergência de plântulas (NAZÁRIO; FERREIRA, 2010). Ademais, temperaturas específicas são requeridas por cada espécie durante a germinação e a formação da plântula (SILVA; SILVA et al., 2006). Devido ao grande número de palmeiras e hábitats, existem variações de temperaturas exigidas para a germinação, de 24 a $35^{\circ} \mathrm{C}$ (LORENZI et al., 2004).

Visto que condições específicas para que ocorra a germinação são requeridas por cada espécie, pesquisas que visem acelerar e uniformizar esse processo têm sido desenvolvidas, com a finalidade de elucidar as condições ótimas de germinação, que forneçam informações importantes acerca da propagação das espécies, concordando com Luz et al. (2011).

A espécie Bactris maraja Mart., vulgarmente conhecida como marajá, é uma palmeira de hábito solitário ou cespitoso, com altura entre 4 e $7 \mathrm{~m}$, cujos estipes medem cerca de $4 \mathrm{~cm}$ de diâmetro, sendo levemente anelados por cicatrizes e espinhosos nos entrenós. Os frutos, na maturidade, apresentam formato obovoide, de coloração roxo-escura e de polpa macia, adocicada e comestível. A planta, de ocorrência natural e frequente em toda a Amazônia, é típica de solos arenosos e encharcados das margens de lagos e igarapés dos subbosques de matas primárias e secundárias de florestas de terra firme e alagada (OLIVEIRA et al., 2006; MIRANDA; RABELO, 2008). Estudos básicos relacionados à germinação das sementes dessa espécie são incipientes, uma vez que a maioria dos trabalhos tem focalizado espécies de maior valor comercial, como os de Luz et al. (2008), Gama et al. (2010) e Rodrigues Junior et al. (2013).

Diante do exposto, o objetivo deste trabalho foi estudar os efeitos de diferentes temperaturas, períodos de secagem do pireno e extração da semente e períodos de embebição da semente na germinação de B. maraja.

\section{MATERIAL E MÉTODOS}

A pesquisa foi conduzida no Setor de Olericultura da Faculdade de Ciências Agrárias da Universidade Federal do Amazonas (UFAM) e no Laboratório de Sementes da Coordenação de Pesquisas em Ciências Agronômicas (CPCA) do Instituto Nacional de Pesquisas da Amazônia (INPA), em Manaus, Amazonas.

Os cachos contendo frutos maduros (coloração roxo-escura) foram coletados, em maio de 2012, de 25 plantas em ambiente de várzea, no Município do Careiro da Várzea, Amazonas. O material botânico foi colhido para identificação e confecção de exsicatas, que foram posteriormente incluídas no Herbário da Universidade Federal do Amazonas, sob os números de registro 9279, 9280 e 9281.

O estudo foi constituído por três experimentos independentes. Extraíram-se os pirenos manualmente, mediante a remoção do exocarpo, por meio de maceração com rolo de madeira; e do mesocarpo, por fricção em areia sobre peneira.

Experimento 1 - Foram considerados dois níveis de beneficiamento: com remoção do endocarpo e sem remoção do endocarpo. Parte dos pirenos foi submetida à secagem, por um dia, sobre bancada de laboratório (temperatura média mínima de $27^{\circ} \mathrm{C}$ e máxima de $30^{\circ} \mathrm{C}$ ), a fim de favorecer a liberação das sementes adnatas ao endocarpo. As sementes foram extraídas mediante a quebra do endocarpo com o uso de alicate de pressão. Outra parte dos pirenos, após a limpeza, foi mantida em recipiente plástico até a semeadura. 
Em seguida, as sementes com e sem endocarpo foram acondicionadas, separadamente, em sacos plásticos contendo vermiculita de granulometria média (1:1; v:v). O substrato foi umedecido com o volume de água correspondente a $60 \%$ da massa do substrato. Depois de fechados, os sacos foram submetidos a seis diferentes temperaturas $\left(20^{\circ} \mathrm{C}, 25^{\circ} \mathrm{C}, 30^{\circ} \mathrm{C}, 35^{\circ} \mathrm{C}, 40^{\circ} \mathrm{C}\right.$ e 26 $\left.40^{\circ} \mathrm{C}\right)$. A temperatura alternada $\left(26-40^{\circ} \mathrm{C}\right)$ foi regulada por temporizador, durante $6 \mathrm{~h}$ a $40^{\circ} \mathrm{C}$ e $18 \mathrm{~h}$ a $26^{\circ} \mathrm{C}$.

O experimento foi instalado em delineamento inteiramente casualizado, em esquema fatorial ( 2 níveis de beneficiamento x 6 temperaturas) e com quatro repetições de 50 unidades cada.

Experimento 2 - Os pirenos foram submetidos a $0,1,2,3,5,7,9,11,13$ e 15 dias de secagem sobre bancada de laboratório (temperatura média mínima de $27^{\circ} \mathrm{C}$ e máxima de $30^{\circ} \mathrm{C}$ ). À exceção do tratamento zero dia, os pirenos tiveram o endocarpo removido após a secagem. A extração da semente ocorreu conforme descrito no experimento anterior.

Em cada tratamento foi determinado o teor de água pelo método de estufa a $105^{\circ} \mathrm{C} \pm 3^{\circ} \mathrm{C}$, por $24 \mathrm{~h}$ (BRASIL, 2009), utilizando-se quatro repetições de 10 unidades cada. Durante a extração das sementes, foram contabilizadas as sementes totalmente sem endocarpo aderido, sementes com endocarpo parcialmente aderido, sementes intactas (sementes fisicamente íntegras), sementes danificadas (sementes com dano mecânico no tegumento), sementes deterioradas e sementes geminadas.

A semeadura foi realizada em caixas plásticas (50 x 33 x $8 \mathrm{~cm}$ ) contendo vermiculita de granulometria média ( $1: 1 ; \mathrm{v}: \mathrm{v})$, a $2 \mathrm{~cm}$ de profundidade. As caixas foram mantidas em casa de vegetação coberta por agrofilme de 150 micra de espessura, com temperatura média mínima de $26^{\circ} \mathrm{C}$ e máxima de $34^{\circ} \mathrm{C}$. O umedecimento do substrato foi realizado sempre que necessário até o alcance da capacidade de campo.

O delineamento experimental utilizado foi o inteiramente casualizado com 10 tratamentos e quatro repetições de 25 sementes cada.

Experimento 3 - Após a secagem dos pirenos por dois dias, fez-se a extração das sementes conforme o procedimento descrito no Experimento 1. Em seguida, as sementes foram imersas em água por 0, 1, 2, 3, 4 e 5 dias, com substituição diária da água. Após os períodos de embebição, foi realizada a semeadura, conforme descrito no Experimento 1. As sementes foram mantidas em estufa à temperatura alternada de 26-40 ${ }^{\circ} \mathrm{C}$. Em cada tratamento foi determinado o teor de água, utilizando-se quatro repetições de 10 unidades, pelo método de estufa a $105^{\circ} \mathrm{C} \pm 3^{\circ} \mathrm{C}$, por $24 \mathrm{~h}$ (BRASIL, 2009).

O delineamento adotado foi o inteiramente casualizado com seis tratamentos e quatro repetições de 25 sementes cada.

As avaliações dos experimentos foram realizadas a cada 15 dias. Nos testes em laboratório, o critério da germinação foi a formação do botão germinativo, enquanto no teste em viveiro a formação da primeira bainha. Posteriormente, foram calculados a porcentagem de germinação ou emergência (BRASIL, 2009), e o índice de velocidade de germinação ou emergência (MAGUIRE, 1962). No final dos experimentos (8 meses), foi aplicado o teste de corte nas sementes remanescentes (BRASIL, 2009), computando-se a porcentagem de sementes dormentes (sementes com embriões firmes e de coloração branco-leitosa) e de sementes mortas (sementes com embriões deteriorados).

Foram aplicados os testes de normalidade (teste de Lilliefors) e de homogeneidade (teste de Cochran). Os dados da porcentagem de germinação e da emergência foram transformados em $\sqrt{\mathrm{X}+0,5}$ e os dados de porcentagem de sementes dormentes e de sementes mortas, em arcosseno $\sqrt{\mathrm{X} / 100}$. Nos resultados são incluídos os dados originais. A comparação entre as médias do Experimento 1 foi feita pelo teste de Tukey a 1 e $5 \%$ de probabilidade. Os dados referentes aos períodos de secagem e de embebição foram submetidos à análise de regressão. Utilizou-se o software estatístico ASSISTAT (SILVA; AZEVEDO, 2009).

\section{RESULTADOS}

Experimento 1 - A interação entre os fatores (níveis de beneficiamento $\mathrm{x}$ temperaturas) foi significativa nas variáveis analisadas, com exceção do índice de velocidade de germinação, conforme mostrado na Tabela 1.

Independentemente do nível de beneficiamento, as sementes submetidas à temperatura alternada de 26-40 ${ }^{\circ} \mathrm{C}$ apresentaram maior porcentagem de germinação. Na temperatura de $40^{\circ} \mathrm{C}$, o valor obtido pelas sementes com endocarpo foi superior ao da semente sem endocarpo. As sementes submetidas às temperaturas

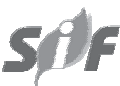

Revista Árvore, Viçosa-MG, v.38, n.5, p.857-865, 2014 
constantes de 20,25 , 30 e $35^{\circ} \mathrm{C}$ apresentaram resultados inferiores. A germinação foi nula nas sementes com endocarpo submetidas a essas temperaturas e, embora as sementes sem endocarpo tenham germinado nas temperaturas de 30 e $35^{\circ} \mathrm{C}$, as porcentagens foram baixas.

No índice de velocidade de germinação, diferenças significativas foram verificadas somente entre os níveis de cada fator (Tabela 1). O maior valor dessa variável foi obtido pelas sementes sem endocarpo $(0,059)$ e por aquelas submetidas à temperatura de $26-40^{\circ} \mathrm{C}(0,291)$.

A maior porcentagem de sementes dormentes foi alcançada pelas sementes com endocarpo nas temperaturas de 20 e $25^{\circ} \mathrm{C}$, não diferindo entre si (Tabela 1 ). As sementes com endocarpo apresentaram valores superiores em todas as temperaturas constantes. As sementes na temperatura 26- $40^{\circ} \mathrm{C}$ exibiram a menor porcentagem para essa variável.

O maior percentual de sementes mortas foi obtido pelas sementes sem endocarpo, sobretudo na temperatura de $40^{\circ} \mathrm{C}$ (Tabela 1). A menor porcentagem foi obtida pelas sementes com endocarpo a $20^{\circ} \mathrm{C}$, não diferindo significativamente das sementes com endocarpo a $25{ }^{\circ} \mathrm{C}$.

Experimento 2 - No primeiro dia de secagem, obteve-se o rendimento de apenas $29 \%$ de sementes completamente sem endocarpo, $71 \%$ de sementes com endocarpo parcialmente aderido, 54\% de sementes intactas e $44 \%$ de sementes danificadas (Figura 1). A partir do segundo dia de secagem, o rendimento percentual aumentou acentuadamente, em que as sementes sem endocarpo e as intactas apresentaram valores superiores a 70 e $60 \%$, respectivamente. Entretanto, a porcentagem de sementes com endocarpo parcialmente aderido e de sementes danificadas decresceu para menos de 30 e $40 \%$, respectivamente. Até o final do processo, correspondente a 15 dias de secagem, houve redução quase que total das sementes sem endocarpo aderido. As porcentagens de sementes deterioradas e geminadas foram praticamente constantes no período.

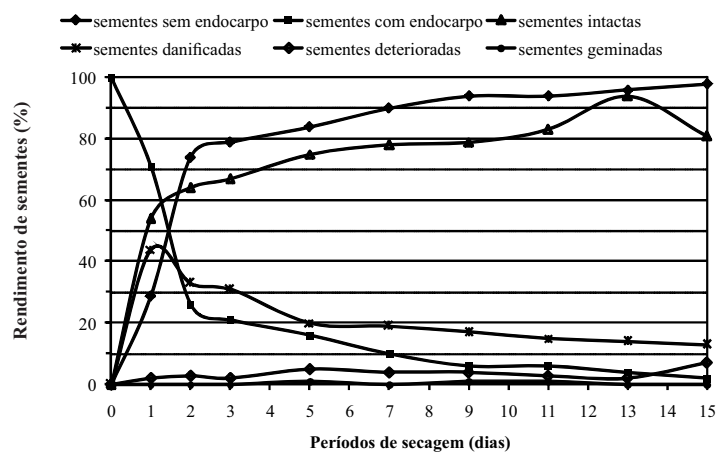

Figura 1 - Rendimento das sementes de B. maraja, após a remoção do endocarpo, em função do período de secagem dos pirenos.

Figure 1-Seed yield of B. maraja, after removal of the endocarp, depending on the drying time of pyrenes.

Tabela 1 - Médias da germinação (G), do índice de velocidade de germinação (IVG), de sementes dormentes (SD) e de sementes mortas (SM) de B. maraja, em função dos níveis de beneficiamento e das temperaturas.

Table 1 - Germination averages (G), the germination speed index (GSI) of dormant seeds (DS) and dead seeds (DS) of B. maraja according to the levels of processing and temperatures.

\begin{tabular}{|c|c|c|c|c|c|c|c|c|}
\hline & \multirow{2}{*}{$\begin{array}{c}\text { Nível de } \\
\text { Beneficiamento }\end{array}$} & \multicolumn{6}{|c|}{ Temperatura (C) } & \multirow[t]{2}{*}{ Médida } \\
\hline & & 20 & 25 & 30 & 35 & 40 & $26-40$ & \\
\hline G (\%) & $\begin{array}{l}\text { com endocarpo } \\
\text { sem endocarpo }\end{array}$ & $\begin{array}{l}0 \mathrm{aC} \\
0 \mathrm{aD}\end{array}$ & $\begin{array}{l}0 \mathrm{aC} \\
0 \mathrm{aD}\end{array}$ & $\begin{array}{c}\mathrm{ObC} \\
2 \mathrm{aCD}\end{array}$ & $\begin{array}{c}\mathrm{ObC} \\
3 \mathrm{aBc}\end{array}$ & $\begin{array}{l}11 \mathrm{aB} \\
5 \mathrm{bB}\end{array}$ & $\begin{array}{l}71 \mathrm{aA} \\
64 \mathrm{aA}\end{array}$ & \\
\hline $\mathrm{CV}(\%)$ & \multicolumn{8}{|c|}{13,24} \\
\hline $\begin{array}{c}\text { IVG } \\
\text { Média }\end{array}$ & $\begin{array}{l}\text { com endocarpo } \\
\text { sem endocarpo }\end{array}$ & $\begin{array}{c}0,000 \\
0,000 \\
0,000 \mathrm{C}\end{array}$ & $\begin{array}{c}0,000 \\
0,000 \\
0,000 \mathrm{C}\end{array}$ & $\begin{array}{c}0,000 \\
0,012 \\
0,006 \mathrm{BC}\end{array}$ & $\begin{array}{c}0,000 \\
0,017 \\
0,008 B C\end{array}$ & $\begin{array}{c}0,023 \\
0,028 \\
0,026 B\end{array}$ & $\begin{array}{c}0,284 \\
0,298 \\
0,291 \mathrm{~A}\end{array}$ & $\begin{array}{l}0,051 b^{*} \\
0,059 a *\end{array}$ \\
\hline CV (\%) & \multicolumn{8}{|c|}{24,52} \\
\hline SD (\%) & $\begin{array}{l}\text { com endocarpo } \\
\text { sem endocarpo }\end{array}$ & $\begin{array}{l}100 \mathrm{aA} \\
75 \mathrm{bA}\end{array}$ & $\begin{array}{c}99 a A B \\
78 b A\end{array}$ & $\begin{array}{l}96 \mathrm{aBC} \\
64 \mathrm{bAB}\end{array}$ & $\begin{array}{l}\text { 93aCD } \\
\text { 71bAB }\end{array}$ & $\begin{array}{l}84 \mathrm{aD} \\
52 \mathrm{bB}\end{array}$ & $\begin{array}{l}20 a E \\
19 a C\end{array}$ & \\
\hline CV (\%) & \multicolumn{8}{|c|}{8,6} \\
\hline SM (\%) & $\begin{array}{l}\text { com endocarpo } \\
\text { sem endocarpo }\end{array}$ & $\begin{array}{c}\text { ObC } \\
25 \mathrm{aAB}\end{array}$ & $\begin{array}{l}1 \mathrm{bBC} \\
22 \mathrm{aB}\end{array}$ & $\begin{array}{c}4 \mathrm{bAB} \\
34 \mathrm{aAB}\end{array}$ & $\begin{array}{c}7 \mathrm{bA} \\
26 \mathrm{aAB}\end{array}$ & $\begin{array}{l}5 \mathrm{bAB} \\
43 \mathrm{aA}\end{array}$ & $\begin{array}{c}9 \mathrm{aA} \\
17 \mathrm{aB}\end{array}$ & \\
\hline$\overline{C V(\%)}$ & \multicolumn{8}{|c|}{24,96} \\
\hline
\end{tabular}

Médias seguidas de mesma letra minúscula na coluna e maiúscula na linha não diferem significativamente entre si, pelo teste de Tukey a $1 \%$ de probabilidade. Letras seguidas de * diferem entre si, a $5 \%$ de probabilidade.

Averages followed by same small letter in the column and capital letter in the line do not differ significantly by Tukey test at $1 \%$ probability. Letters followed by * differ at $5 \%$ probability.

Revista Árvore, Viçosa-MG, v.38, n.5, p.857-865, 2014 
O teor de água das sementes, no período de 15 dias de secagem, reduziu de 23,6\% (inicial) para 7,8\% (final) (Figura 2). A redução mais acentuada ocorreu até o terceiro dia de secagem, registrando-se 8,4\% do teor de água perdido desde o início do processo. A partir desse período, a perda diária do conteúdo de água foi observada em menos de $1 \%$.

A emergência de plântulas apresentou comportamento linear decrescente em função do período de secagem (Figura 2). A porcentagem inicial de 49\%, ao zero dia de secagem, decresceu para $37 \%$ aos 15 dias de secagem.

O índice de velocidade de emergência (IVE) foi variável ao longo do período de secagem, porém decrescente (Figura 2). O valor aumentou somente até o segundo dia de secagem, decrescendo a partir do terceiro dia, com pequena variação crescente com 13 dias, voltando a decrescer até os 15 dias de secagem.

A porcentagem de sementes dormentes, da mesma forma, apresentou comportamento irregular, declinando com o aumento do período de secagem, sendo o maior percentual apresentado pelos pirenos não submetidos à secagem (Figura 2).

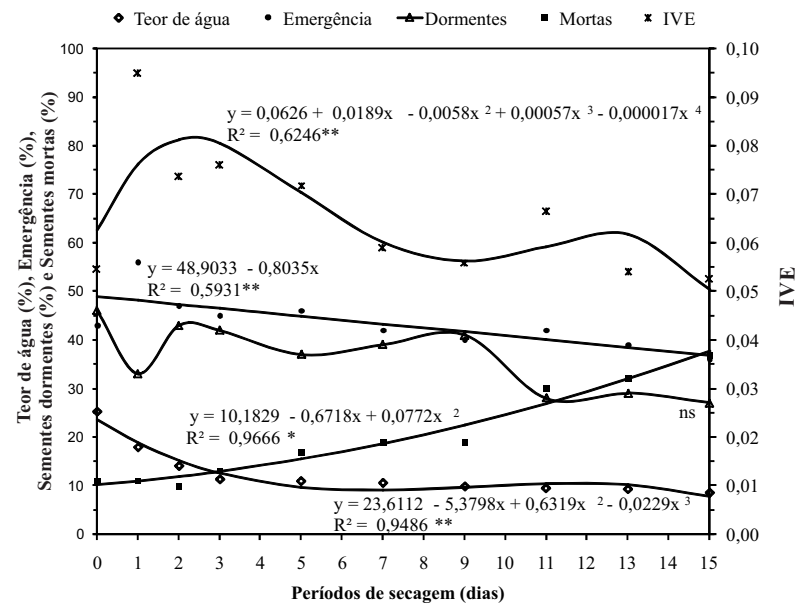

Figura 2 - Teor de água, emergência, índice de velocidade de emergência (IVE), sementes dormentes e sementes mortas referentes a sementes de B. maraja submetidas a diferentes períodos de secagem. Ns: não significativo; ** e * significativos a $1 \%$ e $5 \%$ de probabilidade, respectivamente.

Figure 2 - Water content, emergence, emergence speed index (ESI), dormant seeds and dead seeds related to seeds of B. maraja submitted to different drying periods. ns: not significant; ** and *: significant at $1 \%$ and $5 \%$ probability, respectively.
A porcentagem de sementes mortas aumentou em função do período de secagem (Figura 2). A taxa de mortalidade de $10 \%$ nas sementes não submetidas à secagem aumentou gradativamente até alcançar o maior valor de 38\% nas sementes secas por 15 dias.

Experimento 3 - O teor de água das sementes de $B$. maraja aumentou de $13,8 \%$ nas sementes sem embebição para 31,0\% nas sementes embebidas por cinco dias, somando acréscimo de $17,2 \%$ no teor de água durante o processo. O maior registro foi observado logo após o primeiro dia de embebição, estabilizando a partir do segundo dia (Figura 3).

A porcentagem de germinação apresentou tendência quadrática em função do período de embebição das sementes. $\mathrm{O}$ valor inferior nas sementes não embebidas (74\%) prosseguiu de forma crescente até alcançar o valor máximo de $90 \%$ nas sementes embebidas por dois dias, decrescendo, em seguida, até atingir $81 \%$ ao final do processo (Figura 3).

As sementes remanescentes não foram afetadas pelos períodos de embebição. Contudo, a porcentagem de sementes dormentes prosseguiu constante ao longo do processo. Enquanto o percentual de sementes mortas foi elevado nas sementes sem embebição (19\%), declinando no segundo dia de embebição, obtendo

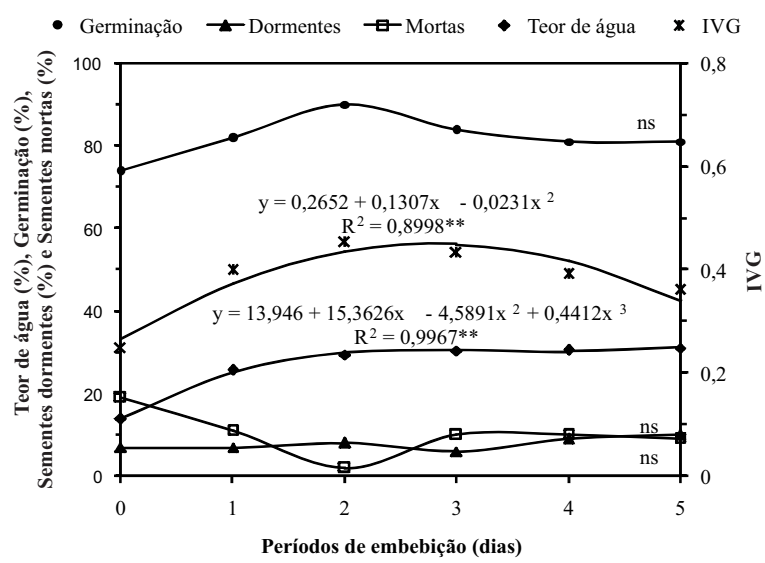

Figura 3 - Teor de água, germinação, índice de velocidade de germinação(IVG), sementes dormentes e sementes mortas referentes a sementes de $B$. maraja submetidas a diferentes períodos de embebição. ns: não significativo; $\mathrm{e}^{* *}$ : significativo a $1 \%$ de probabilidade.

Figure 3 - Water content, germination, germination speed index (GSI), dormant seeds and dead seeds related to seeds of B. maraja submitted to different periods of soaking. ns: not significant; and **: significant at $1 \%$ probability.

Revista Árvore, Viçosa-MG, v.38, n.5, p.857-865, 2014 
o menor valor ( $2 \%$ ) e elevando-se novamente no terceiro dia, com tendência constante até o quinto dia (Figura 3).

O índice de velocidade de germinação, inicialmente baixo nas sementes não embebidas, aumentou progressivamente até o período de dois dias de embebição, decrescendo a partir de três dias até o final do processo, aos cinco dias de embebição (Figura 3).

\section{DISCUSSÃO}

Comumente, às sementes de palmeiras é atribuída a dormência causada pela resistência mecânica ou a impermeabilidade à água impostas, em parte, pelo endocarpo pétreo (OROZCO-SEGOVIA et al., 2003; FERREIRA; GENTIL, 2006). A remoção do endocarpo tem sido utilizada com as finalidades de acelerar e uniformizar a germinação e aprimorar o manejo de sementes e produção de mudas de algumas espécies de palmeiras, como Astrocaryum aculeatum Mey. (FERREIRA; GENTIL, 2006) e Acrocomia aculeata Lodd. ex Mart. (RUBIO NETO et al., 2012). No entanto, em Bactris gasipaes Kunth (LEDO et al., 2002) a remoção do endocarpo não diferiu da testemunha (sementes com endocarpo). Na espécie B. maraja, apesar de a presença do endocarpo não ter interferido na germinação, o uso de sementes livres acelerou o processo.

Ademais, a presença do endocarpo provavelmente desempenha proteção adicional à conservação da viabilidade das sementes de B. maraja, visto pela maior porcentagem de sementes dormentes e pela menor porcentagem de sementes mortas obtidas pelas sementes com endocarpo. Embora as sementes sem endocarpo tenham apresentado maior mortalidade, isso pode ter ocorrido em função do procedimento de extração, considerando que, para a remoção do endocarpo, os pirenos foram submetidos a apenas um dia de secagem, o que pode ter ocasionado injúrias.

Segundo Ferreira e Gentil (2006), a remoção do endocarpo rígido das sementes de palmeiras sempre oferece riscos à integridade física das sementes, podendo acarretar danos tanto ao tegumento quanto ao endosperma e ao embrião. A íntima ligação do endocarpo ao tegumento pode estar associada à dificuldade na extração da semente do endocarpo. Portanto, segundo Rubio Neto et al. (2012), o processo de extração da semente de palmeiras deve ser otimizado para cada espécie, considerando que há variação quanto à rigidez do endocarpo, ao tamanho e teor de água da semente, bem como ao instrumento utilizado para a extração desta. Em Astrocaryum aculeatum, mesmo depois de 30 dias de secagem dos pirenos, com redução de 31,1\% do teor de água inicial, houve perda de aproximadamente $30 \%$ das sementes após a quebra do endocarpo (NAZÁRIO; FERREIRA, 2010).

Em algumas espécies de palmeiras, como Astrocaryum aculeatum (FERREIRA; GENTIL, 2006) e Acrocomia aculeata (RUBIO NETO et al., 2012), a prévia secagem dos pirenos facilitou a remoção do endocarpo, que beneficiou a porcentagem e a velocidade de germinação.

A secagem progressiva dos pirenos de $B$. maraja facilitou o desprendimento do endocarpo adnato ao tegumento das sementes e, consequentemente, facilitou a extração delas. Entretanto, não há a necessidade de remoção do endocarpo, pois, apesar da secagem dos pirenos por um dia e de a extração das sementes haver aumentado o índice de velocidade de emergência de plântulas, nesse período a porcentagem de sementes danificadas foi acentuada; e, ainda que esses danos tenham sido reduzidos com dois dias de secagem, a emergência de plântulas igualmente decresceu. A partir disso, houve decréscimo na velocidade de emergência de plântulas até o final do processo. Além disso, observou-se pouca variação, em termos de valores absolutos, do percentual de emergência de plântulas nos pirenos não submetidos à secagem e extração em relação aos pirenos submetidos ao beneficiamento.

Na avaliação da emergência de plântulas, tanto o método de secagem quanto o teor de água perdido ao longo do processo de dessecação das sementes devem ser levados em consideração, com o intuito de esclarecer o comportamento fisiológico delas (RUBIO NETO et al., 2012). Bovi et al. (2004) verificaram, em Bactris gasipaes, que a secagem das sementes até oito dias reduziu o teor de água e influenciou significativamente a viabilidade e vigor delas.

O teor de água inicial das sementes de B. maraja de 25,2\% foi próximo ao apresentado por outras espécies de palmeiras, como Astrocaryum aculeatum (NAZÁRIO; FERREIRA, 2010) e Acrocomia aculeata (RUBIO NETO et al., 2012), ou seja, em torno de $29 \%$. Entretanto, foi inferior quando comparado com o das espécies $B$. gasipaes (BOVI et al., 2004) e Euterpe oleraceae Mart. (NASCIMENTO; SILVA, 2005), cujo teor de água inicial 
foi de $47 \%$ em ambas. O teor de água inicial de sementes fisiologicamente maduras pode ser atribuído, em parte, ao material genético, bem como aos dias decorridos após a colheita dos frutos até o início do experimento (MARTINS et al., 2009).

O baixo teor de água inicial (25,2\%) e final (8,5\%), alcançado após a secagem por 15 dias, indicou que as sementes não apresentam comportamento recalcitrante. Porém, são necessários testes específicos de tolerância à dessecação, armazenamento e viabilidade para determinar a respectiva classificação fisiológica.

A ausência do endocarpo pode acelerar a embebição das sementes, como foi observado em Astrocaryum aculeatum por Ferreira e Gentil (2006). Em sementes de Acrocomia aculeata, o tegumento não consiste em barreira à absorção de água; contudo, a remoção do opérculo aumenta a velocidade de absorção de água pelo embrião(RIBEIRO et al., 2011; RODRIGUES JUNIOR et al., 2013). Pérez et al. (2008) verificaram que os envoltórios da semente de Pritchardia remota Beck. são permeáveis, pois ocorre a embebição, ainda que lentamente. Em B. maraja, tanto o endocarpo quanto o tegumento não apresentam impermeabilidade, uma vez constatados a redução do teor de água do pireno e o acréscimo do teor de água da semente.

A absorção de água na semente pode influenciar diretamente a germinação, seja promovendo, seja inibindo o processo. Segundo Marcos Filho (2005), a reidratação dos tecidos desencadeia uma série de atividades metabólicas, que resultam na retomada do crescimento do eixo-embrionário. Entretanto, o excesso de umidade, em geral, causa decréscimo na germinação, uma vez que impede a penetração do oxigênio e reduz todo o processo metabólico resultante.

Estudos realizados com espécies de palmeiras registram os efeitos benéficos da embebição das sementes sobre a germinação, levando em conta que períodos distintos desse processo são requeridos para cada espécie. Em Astrocaryum aculeatum, a embebição das sementes até nove dias aceleram e aumentam a germinação(FERREIRA; GENTIL, 2006). Nazário e Ferreira (2010), também estudando sementes de A. aculeatum, verificaram resultados superiores para todas as variáveis das sementes embebidas. A embebição foi eficiente por um a dois dias para Syagrus coronata Becc. (CARVALHO et al., 2005) e Copernicia alba Morong (FAVA et al., 2011) e por 12 dias para Copernicia prunifera Moore (SILVA et al., 2009).
Em algumas espécies, no entanto, a imersão das sementes em água pode ser prejudicial, não sendo recomendada. As sementes de Pritchardia remota não germinaram quando submetidas a $336 \mathrm{~h}$ de embebição (PÉREZ et al., 2008). Em sementes de Archontophoenix cunninghamii Wendl. \& Drude (LUZ et al., 2011) e Acrocomia aculeata (RUBIO NETO et al., 2012), a aplicação desse pré-tratamento não beneficiou a porcentagem e velocidade de germinação, visto que os resultados foram inversamente proporcionais ao tempo de embebição. Já em alguns casos a imersão em água pode não exercer nenhum efeito significativo sobre a germinação, como em Bactris gasipaes (LEDO et al., 2002), em que não houve diferença estatística entre os pré-tratamentos.

As temperaturas favoráveis à germinação de sementes variam conforme a espécie. Algumas espécies de palmeiras obtêm resultados exitosos de germinação em temperaturas constantes, como $25^{\circ} \mathrm{C}$ para Copernicia prunifera (REIS et al., 2010), $30^{\circ} \mathrm{C}$ para Oenocarpus minor Mart. (SILVA; SILVA et al., 2006) e $35^{\circ} \mathrm{C}$ para Thrinax parviflora Swartz (PIVETTA et al., 2005a). Entretanto, outras espécies podem apresentar resultados superiores em temperaturas alternadas, como 20-30 ${ }^{\circ} \mathrm{C}$ em Phoenix canariensis Chabaud (PIMENTA et al., 2010) e $25-30{ }^{\circ} \mathrm{C}$ em Dypsis decaryi Beentje \& J. Dransf. (LUZ et al., 2008). Ademais, tanto temperaturas constantes quanto alternadas podem ser benéficas para algumas espécies, como $15-20$ e $20-25{ }^{\circ} \mathrm{C}$ em Chamaerops humilis L. (GONZÁLEZ-BENITO et al., 2006) e 20-30 e 30-35 ${ }^{\circ} \mathrm{C}$ em Euterpe oleracea (GAMA et al., 2010). Baixa temperatura também parece ser fator limitante da germinação de outras espécies de palmeiras, sendo afetada ou completamente inibida, como Archontophoenix cunninghamii (PIVETTA et al., 2008) a 15 e $20^{\circ} \mathrm{C}$ e Syagrus romanzoffiana Glass a $20^{\circ} \mathrm{C}$ (PIVETTA et al., 2005b). A temperatura, em alguns casos, pode não exercer influência significativa sobre a porcentagem de germinação, contudo pode acelerar o processo, como observado em Oenocarpus bacaba Mart. (JOSÉ et al., 2012).

As sementes de $B$. maraja apresentaram melhor desempenho sob temperatura alternada de $26-40{ }^{\circ} \mathrm{C}$. A temperatura ideal para a germinação geralmente está relacionada à faixa de temperatura típica do local de ocorrência da espécie, na época favorável à germinação das sementes e ao estabelecimento das plântulas (RAMOS; VARELA, 2003). Segundo Marcos Filho(2005),

Revista Árvore, Viçosa-MG, v.38, n.5, p.857-865, 2014 
em geral espécies não domesticadas e cujas sementes apresentam dormência requerem para a germinação alternância de temperatura, típica do hábitat natural, uma vez que essa variação promove alteração no balanço hormonal.

Por fim, o maior percentual de sementes dormentes de B. maraja, apresentado nas temperaturas de 20 e $25^{\circ} \mathrm{C}$, indicou que tais temperaturas podem ser adequadas ao seu armazenamento.

\section{CONCLUSÃO}

A secagem do pireno facilitou a remoção do endocarpo e aumentou o rendimento do processo de extração das sementes. No entanto, o procedimento não é recomendado, pois, além de prejudicar a germinação e o vigor da semente, esta não apresenta dormência causada pela resistência mecânica do endocarpo.

A embebição das sementes por dois dias foi benéfica à germinação. Porém, como foi observado que o endocarpo não é impermeável à água, os próprios pirenos podem ser submetidos à embebição antes da semeadura.

A temperatura alternada de $26-40{ }^{\circ} \mathrm{C}$ foi a mais favorável à germinação de $B$. maraja.

\section{AGRADECIMENTOS}

À Fundação de Amparo à Pesquisa do Estado do Amazonas (FAPEAM), pela concessão de bolsa de estudo; e ao Conselho Nacional de Desenvolvimento Científico e Tecnológico (CNPq), pelo apoio financeiro.

\section{REFERÊNCIAS}

BRASIL. Ministério da Agricultura, Pecuária e Abastecimento. Regras para análise de sementes. Brasília: Secretaria Nacional de Defesa da Agropecuária, 2009. 399p.

BOVI, M. L. A.; MARTINS, C. C.; SPIERING, S. H. Desidratação de quatro lotes de pupunheira: efeitos sobre a germinação e o vigor. Horticultura Brasileira, v.22, n.1, p.109-112, 2004.

CARVALHO, N. O. S. et al. Uso de substâncias reguladoras e não-específicas na germinação de sementes de licuri (Syagrus coronata (Mart.) Becc). Sitientibus, v.5, n.1, p.28-32, 2005.
FAVA, C. L. F.; ALBUQUERQUE, M. C. F. Emergência de plântulas de Copernicia alba (Morong ex Morong e Britton) em função da escarificação mecânica e imersão de sementes em água corrente. Revista Brasileira de Horticultura Ornamental, v.17, n.2, p.127-132, 2011.

FERREIRA, S. A. N.; GENTIL, D. F. O. Extração, embebição e germinação de sementes de tucumã (Astrocaryum aculeatum). Acta Amazonica, v.36, n.2, p.141-146, 2006.

FERREIRA, S. A. N.; CASTRO, A. F.; GENTIL, D. F. O. Emergência de plântulas de tucumã (Astrocaryum aculeatum) em função do prétratamento das sementes e da condição de semeadura. Revista Brasileira de Fruticultura, v.32, n.4, p.1189-1195, 2010.

GAMA, J. S. N. et al. Temperaturas e substratos para germinação e vigor de sementes de Euterpe oleraceae Mart. Revista Ciência Agronômica, v.41, n.4, p.664-670, 2010.

GONZÁLEZ-BENITO, M.E.; HUERTAS-MICÓ, M.; PÉREZ-GARCÍA, F. Seed germination and storage of Chamaerops humilis (dwarf fan palm). Seed Science and Technology, v.34, n.1, p.143-150, 2006.

JOSÉ, A. C.; ERASMO, E. A. L.; COUTINHO, A. B. Germinação e tolerância à dessecação de sementes de bacaba (Oenocarpus bacaba Mart.). Revista Brasileira de Sementes, v.34, n.4, p.651-657, 2012.

LEDO, A. S. et al. Efeito do tamanho da semente, do substrato e pré-tratamento na germinação de sementes de pupunha. Revista Ciência Agronômica, v.33, n.1, p.29-32, 2002.

LORENZI, H. et al. Palmeiras brasileiras e exóticas cultivadas. Nova Odessa: Plantarum, 2004. 272p.

LUZ, P. B. et al. Germinação de sementes de Dypsis decaryi (Jum.) Beentje \& J. Dransf. (Arecaceae). Ciência e Agrotecnologia, v.32, n.5, p.1461-1466, 2008.

LUZ, P. B. et al. Germinação de sementes de palmeira-real-australiana (Archontophoenix cunninghamii) sob efeito da imersão em água. Revista Agrarian, v.4, n.11, p.27-32, 2011. 
MAGUIRE, J. D. Speed of germination: aid in selection and evaluation for seedling emergence and vigour. Crop Science, v.2, p.176-177, 1962.

MARCOS FILHO, J. Fisiologia de sementes de plantas cultivadas. Piracicaba: Fealq. Biblioteca de Ciências Agrárias, 2005. v.12. 495p.

MARTINS, C. C. et al. Secagem e armazenamento de sementes de juçara. Revista Árvore, v.33, n.4, p.635-642, 2009.

MIRANDA, I. P. A.; RABELO, A. Guia das palmeiras de Porto Trombetas/PA. Manaus: Universidade Federal do Amazonas, Instituto Nacional de Pesquisas da Amazônia, 2008. 365p.

NASCIMENTO, W. M. O.; SILVA, W. R. Comportamento fisiológico de sementes de açaí (Euterpe oleracea Mart.) submetidas à desidratação. Revista Brasileira de Fruticultura, v.27, n.3, p.349-351, 2005.

NAZÁRIO, P.; FERREIRA, S. A. N. Emergência de plântulas de Astrocaryum aculeatum G. May. em função da temperatura e do período de embebição das sementes. Acta Amazonica, v.40, n.1, p.165-170, 2010.

OLIVEIRA, J.; POTIGUARA, R. C. V.; LOBATO, L. C. B. Fibras vegetais utilizadas na pesca artesanal na microrregião do Salgado, Pará. Boletim Museu Paraense Emílio Goeldi, v.1, n.2, p.113-127, 2006.

OROZCO-SEGOVIA, A. et al. Seed biology of palms: a review. Palms, v.47, n.2, p.79-94, 2003.

PÉREZ, H. E.; CRILEY, R. A.; BASKIN, C. C. Promoting germination in dormant seeds of Pritchardia remota (Kuntze) Beck., an endangered palm endemic to Hawaii. Natural Areas Journal, v.28, n.1-3, p.251-260, 2008.

PIMENTA, R. S. et al. Efeito da maturação e temperatura na germinação de sementes de Phoenix canariensis hort. Ex Chabaud - ARECACEAE. Revista Árvore, v.34, n.1, p.31-38, 2010.

PIVETTA, K. F. L. et al. Efeito da temperatura e do armazenamento na germinação de sementes de Thrinax parviflora Swartz. (Arecaceae).

Científica, v.33, n.2, p.178-184, 2005a.
PIVETTA, K. F. L. et al. Effects of temperature on seed germination of Queen Palm Syagrus romanzoffiana (Cham.) Glassman. (Arecaceae). Acta Horticulturae, v.683, p.379-381, 2005b.

PIVETTA, K. F. L. et al. Tamanho do diásporo, substrato e temperatura na germinação de sementes de Archontophoenix cunninghamii (Arecaceae). Revista de Biologia e Ciências da Terra, v.8, n.1, p.126-134, 2008.

RAMOS, M. B. P.; VARELA, V. P. Efeito da temperatura e do substrato sobre a germinação de sementes de visgueiro do igapó (Parkia discolor Benth) Leguminosae, Mimosoideae. Revista de Ciências Agrárias, n.39, p.135-143, 2003.

REIS, R. G. E. et al. Biometria e efeito da temperatura e tamanho das sementes na protrusão do pecíolo cotiledonar de carnaúba. Revista Ciência Agronômica, v.41, n.1, p.81-86, 2010.

RIBEIRO, L. M. et al. Overcoming dormancy in macaw palm diaspores, a tropical species with potential for use as bio-fuel. Seed Science and Technology, v.39, p.303-317, 2011.

RODRIGUES JUNIOR, A. G. et al. Water uptake and pre-germination treatments in macaw palm (Acrocomia aculeata - Arecaceae) seeds. Journal of Seed Science, v.35, n.1, p.99-105, 2013.

RUBIO NETO, A. et al. Effect of drying and soaking fruits and seeds on germination of macaw palm (Acrocomia aculeata [Jacq.] Loddiges ex MART.). Acta Scientiarum Agronomy, v.34, n.2, p.179-185, 2012.

SILVA, F. A. S. E.; AZEVEDO, C. A. V. Principal components analysis in the software assistatstatistical attendance. In: WORLD CONGRESS ON COMPUTERS IN AGRICULTURE, 7., 2009, Reno. Proceedings... Reno: American Society of Agricultural and Biological Engineers, 2009.

SILVA, F. D. B. et al. Pré-embebição e profundidade de semeadura na emergência de Copernicia prunifera (Miller) H. E. Moore. Revista Ciência Agronômica, v.40, n.2, p.272-278, 2009.

SILVA, B. M. S. et. al. Germinação de sementes e emergência de plântulas de Oenocarpus minor Mart. (ARECACEAE). Revista Brasileira de Fruticultura, v.28, n.2, p.289-292, 2006.

Revista Árvore, Viçosa-MG, v.38, n.5, p.857-865, 2014 